\title{
Noise Induced Hearing Loss among Aircrews of Bangladesh Air Force
}

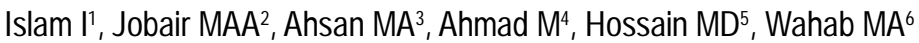

DOI: https://doi.org/10.3329/jafmc.v16i1.53827

\begin{abstract}
Introduction: Noise-induced hearing loss is a significant, often unrecognized health problem among the military pilots. Advanced aircraft are powerful and more efficient but generate high noise causing noise-induced hearing loss (NIHL) among military pilots.
\end{abstract}

Aim: To determine the prevalence of noise-induced hearing loss among pilots of the Bangladesh Air Force (BAF) and its association with aircraft type and flying hours.

Methods: This cross-sectional study was carried out at Central Medical Board (CMB), Bangladesh Air Force (BAF) Dhaka from April 2017 to March 2018. The audiometry was done in the ENT department of CMB, BAF. Pure-tone audiometry was used to measure hearing thresholds and following pure tone frequencies were used for the test: $0.25,0.5,1,2,3,4,6$ and $8 \mathrm{kHz}$. The association between flight hours and the development of noise-induced hearing loss was analyzed in the different age groups.

Results: The study revealed NIHL in the aircrew was $16.5 \%$ with a higher prevalence among the helicopter pilots (18.6\%) as compared with fighter (16.7\%) and transport (11.5\%) pilots. The left ear was affected in most of the cases than the right ear. Pilots of more than 40 years old and $\geq 1500$ flying hours had a significantly higher hearing threshold compared with other categories.

Conclusion: Exposure to noise in aircrew is unavoidable. By avoiding prolonged exposure to loud noise environments and utilization of personal hearing safety devices can prevent noise-induced hearing loss.

Key-words: Noise-induced hearing loss, Aircraft, Pure tone audiometry, Flying hours.

\section{Introduction}

Noise-induced hearing loss (NIHL) is one of the most common types of occupational hearing loss. NIHL is a reduction in auditory acuity following prolonged exposure to loud noise ${ }^{1}$. Generally, prolonged exposure to sounds, louder than $85 \mathrm{~dB}$ is potentially injurious ${ }^{2}$. Military aviators are exposed to high noise that can cause physiological or psychological damage and reduce their quality of life ${ }^{3,4}$. The terminology "Hearing Impairment and NIHL" includes tinnitus, acute acoustic trauma and hearing loss due to continuous or intermittent noise exposure ${ }^{5}$. Exposure to mild to moderate noise can lead to reversible hearing loss, as the temporary threshold shift eventually disappears after a few hours in a quiet environment. However, continuous or repeated exposures to noise eventually lead to irreversible sensory hair cell damage and concomitant permanent sensory neural hearing loss (permanent threshold shift ${ }^{6}$. Noise is also the cause of the discomfort, interference with speech and communication, which eventually produces psychological effects and reduces work efficiency. Hearing loss occurs initially at $4 \mathrm{kHz}$ but gradually spreads to other frequencies ${ }^{7,8}$. Therefore, this study aimed to evaluate the frequency of the NIHL among the BAF flight crew in relation to the duration of the flying time. The audiometry of the individual pilot was analyzed along with a survey of risk factors that might be a contributory factor for hearing loss. So in this study, a special focus was given to age, type of aircraft flown, flying hour, leisure noise exposure, childhood otitis media, acoustic trauma, use of hearing protection aid, otitic barotrauma and smoking habit ${ }^{9}$. At the enrollment in the air force all cadets were examined by audiometry and the normal hearing threshold was $20 \mathrm{~dB}$ or less at any frequency ${ }^{9}$. In NIHL typically the hearing thresholds dip at $4 \mathrm{kHz}$ (acoustic notch) ${ }^{7,10}$ [Figure-1]. The level of hearing loss was assessed basing on the baseline data during entry to the Bangladesh Air Force (BAF). This study will not only help us to formulate safety measures to avoid this burden but also help us to better understand the impact of acoustic trauma on the human ear.

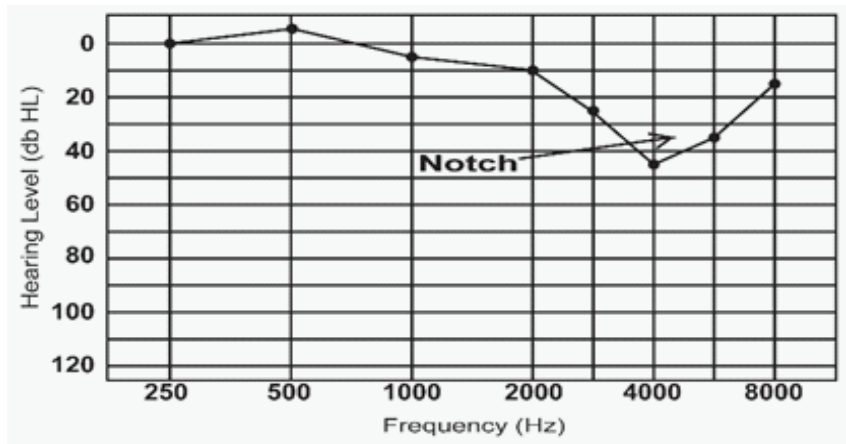

Figure-1: Acoustic notch at $4 \mathrm{kHz}$

\section{Materials and Methods}

This cross-sectional study was carried out at Central Medical Board (CMB), BAF, Dhaka from April 2017 to March 2018. Aircrews who came to the flight surgeon's office for annual medical examination or detailed for any course or United Nations

1. Lt Col Iftekharul Islam, MBBS, DAs Med, Classified Specialist in Aerospace Medicine, Air Headquarters, Bangladesh Air Force (BAF) (E-mail: ifti8151@yahoo.com) 2. Brig Gen Md Abdullah Al Jobair, MBBS, MHI, MPH, Director Medical Services (Air), BAF 3. Col Mohammad Ahmed Ahsan, MBBS, DAs Med, DAv Med, Classified Specialist in Aerospace Medicine, Central Medical Board, BAF 4. Col Mushtaq Ahmad, MBBS, MCPS, DFM, Professor \& Head, Department of Forensic Medicine \& Toxicology, AFMC, Dhaka 5. Lt Col Mohammad Delwar Hossain, MBBS, FCPS, MCPS, DLO, Classified Specialist in ENT, CMH, Dhaka 6. Lt Col Md Abdu Wahab, MBBS, MD, Associate Professor of Biochemistry, AFMC, Dhaka. 
peacekeeping mission were included in this study. All of them were instructed to refrain from loud aircraft noise exposure/any loud noise exposure before audiometry checkup. The audiometry was done in the ENT department of CMB, BAF. Aircrews were individually tested in a sound- proof room. Hearing thresholds were measured by an audiologist in each ear at the following pure-tone frequencies: $0.3,0.5,1,2,3,4,6$ and $8 \mathrm{kHz}$. The thresholds were determined by increasing and decreasing the sound levels of $5 \mathrm{~dB}$ to find the critical value that separates audible from the inaudible range. All individuals who had a hearing loss of more than $20 \mathrm{~dB}$ at any frequency were considered as NIHL positive case. Necessary data were collected from the study subjects by structured questionnaires. The questionnaires included the age, type of aircraft flown, hours of flying, any history of acoustic trauma, barotraumas, history of head injury, use of any ototoxic medication, smoking, exposure to leisure noise and use of hearing aid protection in flight. A difference in the prevalence of hearing loss was assessed using the chi-square test. ANOVA was used to determine the mean hearing thresholds, $p<0.05$ was considered statistically significant. Data were analyzed using SPSS version 21.

\section{Results}

A total of 125 aircrews and aged between 21-48 years have participated in the study. All the subjects were male pilot and their mean age was $33.2 \pm 4.6$ years. Among them 26 were fighter pilot, 34 were transport pilots and 65 were helicopter pilots. Pilots were categorized based on age (20-30, 31-40 and 41-50 years) (Table-I) and flying hours ( $<500,500-1000,1001-1500$ and $\geq 1500$ flying hours) (Table-II). The prevalence of hearing loss in the 20-40 years old age group (9.7\%; $n=9$ ) was statistically different from that in the $41-50$ years old age group $(37.5 \% ; n=12)$ $(p<0.01)$, indicating an increase in age was associated with greater hearing loss. The prevalence of $\mathrm{NIHL}$ among aircrew was $16.8 \%$. Helicopter pilots were found to have a significantly higher prevalence of hearing loss (18.5\%) compared with that of fighter (15.4\%) and transport pilots (14.7\%) (Table-III). Pilots with NIHL $(n=21)$, the most common symptoms associated with NIHL of aircrews was hearing loss seen in $5(23.8 \%)$, followed by difficulty in hearing in noisy surroundings in 4(19.1\%), Discomfort /fullness in the ear 3(14.3\%), affecting social life/difficulty in conversations $2(9.5 \%)$ and $1(4.8 \%)$ developed occasional tinnitus. There were no symptom in a significant number $6(28.6 \%)$ of pilots. Aircrews normal hearing was $83.2 \%$ ( $n=104)$, mild NIHL $13.6 \%(n=17)$ and moderate NIHL $3.2 \%(n=4)$ there were no severe NIHL pilot (Figure-2). The mean of right and left ear hearing threshold (dB) of the helicopter pilot population was higher than the mean of hearing threshold of fighter and transport pilot population. There is a higher hearing threshold in almost all frequencies in the left ear than the right ear indicating NIHL mostly affect the left ear. There is a significant effect $(p<0.05)$ of flying hours and aircraft type on the mean hearing threshold level. Pilots with $\geq 1500$ flying hours experienced a greater hearing loss compared with those in other categories and helicopter pilots with $\geq 1500$ flying hours had a significant higher mean (helicopter pilots mean $\pm S D=23.3 \pm 9.6$ ) hearing threshold than that of fighter and transport pilots (fighter aircraft mean $\pm \mathrm{SD}=18.0 \pm 8.9$ and transport aircraft mean $\pm S D=17.8 \pm 9.5$ ) (Table-IV). The questionnaire analysis in this study found that only $25.7 \%$ of cases had a history of leisure noise exposure, $4.6 \%$ had a history of barotraumas, $0.8 \%$ ( $n=1)$ of the respondents had occasional tinnitus. There were no cases of permanent hearing loss from head injuries sustained outside of work and there was no evidence that any pilot was suffering from a permanent hearing loss as a result of taking medications.

Table-l: Age distribution of the aircrews $(n=125)$

\begin{tabular}{|c|c|c|c|}
\hline Age group & Frequency & \% & Hearing Loss \\
\hline 20-30 Years & 41 & 32.8 & \multirow{2}{*}{$9(9.7 \%)$} \\
\hline $31-40$ Years & 52 & 41.6 & \\
\hline $41-50$ Years & 32 & 25.6 & $12(37.5 \%)$ \\
\hline Mean $\pm S D=33.2 \pm 4.6 ; \quad$ Range $=21-48$ & $\mathrm{p}<0.01$ \\
\hline
\end{tabular}

Table-Il: Flying hours distribution of the pilots $(n=125)$

\begin{tabular}{|c|c|c|c|c|}
\hline \multirow{2}{*}{$\begin{array}{c}\text { Aircraft } \\
\text { type }\end{array}$} & \multicolumn{4}{|c|}{ Flying hours } \\
\cline { 2 - 5 } & $<500$ & $500-1000$ & $1001-1500$ & $\geq 1500$ \\
\hline Fighter & 12 & 08 & 04 & 02 \\
\hline Transport & 10 & 12 & 07 & 05 \\
\hline Helicopter & 21 & 17 & 15 & 12 \\
\hline Total (\%) & $43(34.4)$ & $37(29.6)$ & $26(20.8)$ & $19(15.2)$ \\
\hline
\end{tabular}

Table-III: Prevalence of NIHL among aircrew $(n=125)$

\begin{tabular}{|c|c|c|c|}
\hline \multirow{2}{*}{$\begin{array}{c}\text { Aircraft } \\
\text { type }\end{array}$} & \multicolumn{2}{|c|}{ Number of Aircrews } & \multirow{2}{*}{$\begin{array}{c}\text { p- } \\
\text { value }\end{array}$} \\
\cline { 2 - 3 } & Total & Having hearing loss & \multirow{3}{*}{$>0.05$} \\
\hline Fighter & 26 & $04(15.4 \%)$ & \\
\hline Transport & 34 & $05(14.7 \%)$ & \\
\hline Helicopter & 65 & $12(18.5 \%)$ & \\
\hline Total & 125 & $21(16.8 \%)$ & \\
\hline
\end{tabular}

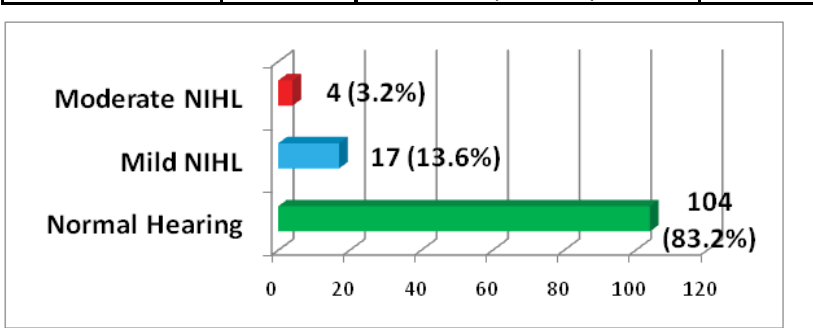

Figure-2: Distribution of heaing status of aircrew $(n=125)$

Table-IV: Mean values of hearing thresholds ( $\mathrm{dB} \mathrm{HL}$ ) among aircraft type and flight hours

\begin{tabular}{|l|c|c|c|c|}
\hline \multirow{2}{*}{ Aircraft type } & \multicolumn{2}{|c|}{ Flyinghours } & \multicolumn{2}{c|}{ Mean( \pm SD) Hearing (dB) } \\
\cline { 2 - 5 } & $<500$ & $500-1000$ & $1001-1500$ & $\geq 1500$ \\
\hline Fighter $(\mathrm{n}=4)$ & $8.5 \pm 4.5$ & $11.7 \pm 6.6$ & $12.3 \pm 4.3$ & $18.0 \pm 8.9^{*}$ \\
\hline Transport $(\mathrm{n}=5)$ & $7.6 \pm 5.3$ & $10.5 \pm 5.4$ & $13.5 \pm 5.5$ & $17.8 \pm 9.5^{*}$ \\
\hline Helicopter $(\mathrm{n}=12)$ & $10.3 \pm 5.6$ & $12.5 \pm 7.4$ & $15.8 \pm 6.6$ & $23.3 \pm 9.6^{* *}$ \\
\hline
\end{tabular}

Note: ANOVA test was done; * $p$-value $<0.05$, ** $p$-value $<0.001$ 


\section{Discussion}

Occupational noise-induced hearing loss is defined as unilateral or bilateral sensorineural hearing loss that develops slowly over a period of several years as the result of exposure to continuous or intermittent loud noise at the workplace. Environmental noise is responsible for hearing loss when workers endure noise exposure for 8 hours to levels above $85 \mathrm{~dB}^{11}$. The first sign of hearing loss from noise exposure is typically a "notching" of the audiogram at 3,4 or $6 \mathrm{kHz}$ greater than $25 \mathrm{~dB}$, with recovery at $8 \mathrm{kHz}^{12,13}$. NIHL is currently one of the most common occupational diseases and the second most frequently self-reported occupational injury. Although NIHL is permanent, irreversible and prevalent, it is preventable. The development of NIHL is affected by many factors, such as individual sensitivity, noise level, noise characteristics, duration of exposure and the effectiveness of noise protection ${ }^{14}$. In this study, $16.5 \%$ of aircrew developed hearing loss and $83.5 \%$ had normal hearing. The hearing loss is mild to moderate at high frequencies. In the current study, for both ears, the audiometric curves of the mean hearing level threshold showed a downward slope from $3 \mathrm{kHz}$ with a notch at $4 \mathrm{kHz}$ and improvement at $8 \mathrm{kHz}$. Among the positive cases, the left ear is affected in the majority of cases than the right ear.

The current study found that aircraft type and its flying hours were significant factors in the prevalence of hearing loss among BAF aircrew with the prevalence of $\mathrm{NIHL}$ being higher among the helicopter pilot with $\geq 1500$ flying hours than that of other categories. A similar type of study was done on French aircrew had found that $29 \%$ of the aircrew had hearing loss and the most affected group was the helicopter pilots who had longer flight hours and the left ear thresholds were lower in all groups which are consistent with this study ${ }^{9}$. In the Belgian Armed Forces, the prevalence ${ }^{15}$ of hearing loss in the military population aged 18-55 years have been found to be high (56\%). In a study on Saudi military pilots the prevalence of noise-induced hearing loss was $18.4 \%$ with a higher prevalence among transport pilots (42\%) as compared with the helicopter pilots $(23 \%)$ and pilots with $\geq 2000$ flying hours had a significantly higher hearing threshold compared with other categories ${ }^{16}$. A study on Kuwait Air Force pilots found $14.5 \%$ developed hearing loss and $85.5 \%$ had normal hearing. The hearing loss is mild to severe at high frequencies ${ }^{17}$. Among the different aircrew populations, the fighter and helicopter pilots were mostly affected than the transport pilots. A study on 178 US Army Aviators found hearing loss was associated with both age and flight hours, both of which are time-dependent factors ${ }^{18}$. It is well established that age influences hearing capacities ${ }^{19}$. A study on 200 helicopter aircrews in the army air corps demonstrated a correlation between hearing loss and the number of years spent in flying ${ }^{20}$. Similarly, Owen found that, among helicopter pilots of the US Army, hearing impairment was related more to the length of flying career and age rather than the number of flight hour ${ }^{21}$.

\section{Conclusion}

The frequency of hearing loss among BAF aircrews, who were exposed to aircraft engine noise for a long time is $16.8 \%$, which is quite alarming. This hearing impairment may not only hazardous for the flight safety but may also lead to or aggravate sensorineural deafness. Noise-induced hearing loss (NIHL) is a common phenomenon in the aviation industry. NIHL usually occurs at high frequencies especially at $4 \mathrm{kHz}$. For military aviators, in addition to aircraft noise other occupational and environmental noise might be the contributing factors. As noise exposure to aircrew is inevitable so hearing loss prevention strategies might play a pivotal role to save aircrews' hearing capacity. Therefore, effective programs for preventing excess hearing loss are strongly recommended with the availability of sound level meters at every air base to monitor the intensity of aircraft engine noise.

\section{References}

1. Baguley DM, McCombe A. Noise-induced hearing loss. In: Gleeson M, Browning GG, Burton MJ, Clarke R et al. Scott Brown's OtolaryngologyHead and Neck Surgery. Hodder Arnold, London 2008:3548-57.

2. Schindler DN, Jackler RK, Robinson S. Occupational hearing loss. In: Lalwani AK, ed. Current diagnosis \& treatment in Otolaryngology-Head \& Neck Surgery. McGraw-Hill, New York 2004:781-92.

3. Seidman MD, Standring RT. Noise and quality of life. Int J Environ Res Public Health 2010; 7:3730-8.

4. Yankaskas K. Prelude: Noise-induced tinnitus and hearing loss in the military. Hear Res 2013; 295:3-8.

5. Helfer TM, Canham-Chervak M, Canada S et al. Epidemiology of hearing impairment and noise-induced hearing injury among U.S. Military personnel, 2003-2005. Am J Prev Med 2010; 38:S71-7.

6. Rajguru R. Military aircrew and noise-induced hearing loss: Prevention and management. Aviat Space Environ Med 2013; 84:1268-76.

7. Rainford DJ and Gradwell DP, Ernsting's Aviation Medicine, 4th ed, London, Hodder Arnold, 2006:720-2, 411-2.

8. Abel SM. Hearing loss in Military Aviation and Other Trades: Investigation of Prevalence and Risk Factors. Aviat Space Environ Med 2005; 76(12):1128-35.

9. Raynal M, Kossowski $M$ and Job A. Hearing in Military Pilots: One-Time Audiometry in Pilots of Fighters, Transports and Helicopters, Aviation, Space and Environmental Medicine 2006; 77:57-61.

10. Ernsting J, Nicholson AN and Rainford DJ. Aviation Medicine, 3rd ed, Great Britain, Butterworth Heinemann, 1999:323-4.

11. Messano GA \& Petti S. General dental practitioners and hearing impairment. Journal of Dentistry 2012; 40:821-8.

12. Krishnamurti S. Sensorineural hearing loss associated with occupational noise exposure: Effects of age-corrections. International Journal of Environmental Research and Public Health 2009; 6:889-99.

13. Verbeek JH, Kateman E, Morata TC et al. Interventions to prevent occupational noise-induced hearing loss. Cochrane Da-tabase Systematic Reviews 2009; 8:CD006396.

14. Nair S and Kashyap RC. Prevalence of noise induced hearing loss in Indian Air Force Personnel. Medical Journal Armed Forces India 2009; 65(3):247-51. 
15. Collée A, Legrand C, Govaerts B et al. Occupational exposure to noise and the prevalence of hearing loss in a Belgian military population: A cross-sectional study. Noise Health 2011; 13:64-70.

16. Al-Omari AS, Al-Khalaf HM, Hussien NF. Association of flying time with hearing loss in military pilots. Saudi J Med Med Sci 2018; 6:155-9.

17. Alam MR, Wahab MA, Rahman MM et al. Prevalence of hearing loss in military aviators: The audiometry and risk factors analysis. JAFMC 2013; 9(1):19-24.
18. Fitzpatrick DT. An analysis of noise-induced hearing loss in army helicopter pilots. Aviat Space Environ Med 1988; 59:937-41.

19. International Organization for Standardization. ISO 7029:2017 AcousticsStatistical Distribution of Hearing Thresholds Related to Age and Gender.

20. Edgington KE, Oelman BJ. An Audiometric survey of army aircrew. Internal Report. HQ Director of Army Aviation, Middle Wallop, Hampshire, England, 1982. 21. Owen MJ. A survey of hearing loss in army aircrew. Occup Med 1996; 46:53-8. 